http://www.inass.org/

\title{
ANFIS Controller for Water Level Control of a Boiler Drum
}

\author{
Bakthavatchalam Hemalatha ${ }^{{ }^{*}}$ \\ Asokan Vimala Juliet ${ }^{2}$

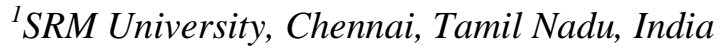 \\ ${ }^{2}$ SRM University, Chennai, Tamil Nadu, India \\ *Corresponding author's Email: hemalathab0378@gmail.com
}

\begin{abstract}
The water level in boiler drum is the critical control parameter to be addressed for providing the efficient and safe operation of steam generators in power plants. The regulation is achieved by using the Artificial Intelligence (AI) technique, namely, Adaptive Neuro-Fuzzy Inference System (ANFIS). It has the capability of self-learning as ANN with the linguistic expression function of fuzzy inference, whose membership functions and fuzzy rules are acquired from a large lot of existing data instead of experience. So, it is well renowned for its control performance in the power system area due to the nonlinear nature and robustness to system parameters uncertainties in multidisciplinary domains and power system too. Here, ANFIS controller takes the error and change of error in water level as inputs to control the actuator of inflow water such that the steam flow out of the steam generator meets the requirement of turbine unit set point which indirectly resembles the demanded load by the Generation System Operator (GSO). The performance of the proposed ANFIS controller is analyzed in terms of tracking the water level set point of boiler drum. For this purpose, a boiler model is developed using the MATLAB/SIMULINK working platform. Then, the proposed ANFIS controller is designed and tested on it for water level regulation. The simulation results are examined and compared with existing FIS technique.
\end{abstract}

Keywords: ANFIS Controller; Water Level; Boiler drum; steam generator; feed water flow; steam flow.

\section{Introduction}

From the past few decades, fossil fuels are being served as energy security for economic and social development of each country in the modern world [1]. But, the efficiency of these power plants is very low and there is a need for reduction in the fuel consumptions as well as specific gas emissions [2, 3]. So, the efficiency of these plants needs to be boosted and higher performance must be accomplished to meet the rapidly changing demand $[4,5,6]$. Because, energy efficiency can only limit demand growth, reduce energy imports and mitigate pollution problems [7]. In the recent years, to meet the efficient power production in a power plant with less economic, emission and human life losses, a major importance has been given to improving the efficiency of boiler units in the respective steam generators $[8,9]$.

Steam boilers are widely used due to their advantageous features such as simplicity, low costs and more particularly their inherent safety $[10,11]$.
Steam generators have basically three functions: generate steam for the power turbine to produce power, be a separating boundary between the primary and secondary water coolant and with the reactor shut down remove the residual reactor heat $[12,13]$. Generally, in the power plants, two configurations exist for electricity generation; first one is boiler-turbine unit, the steam is produced by a single boiler and is fed to a single turbine or in the second configuration, several boilers generate total steam conducted to a collector and then distributed to several turbines [14].

In a power plant, boiler unit is the critical components of a steam generator because of the steam flow rate, temperature and pressure which will greatly affect its performance $[15,16]$. Coming to the boiler unit; steam pressure, temperature, and water level of the drum must be maintained at their respected values during plant operation under various load demands which requires steam in different proportions [17]. And moreover in the boiler-turbine unit of steam generator; drum 
pressure, electric output and water level of drum are adjusted at desired values by manipulation of valve positions for fuel, steam and feed-water flow rates [18]. Among the three valves, it is important to control the drum water level because $30 \%$ of the emergency shutdowns in French PWR plants are caused by poor level control of the steam water level and at critical situations, the shortage of water level will make the boiler explode which is not desirable [19]. So, the dynamics of a boiler unit in steam generator is very different according to the power levels and changes as time goes on and it is a challenging task to improve the water level for better performance [20]. Hence, the water level in a boiler drum plays major role in improving the efficiency of power production in power plant stage.

In the paper, an Artificial Intelligence (AI) based control approach is proposed for water level regulation of a boiler drum. The proposed control technique is based on the ANFIS which is the combination of both Neural Network and Fuzzy Logic Theory. It inherits the best qualities of both AI techniques and neglects the drawbacks in them for better performance in the controlling processes. Here, the ANFIS controller takes the error and change of error in water level as inputs to control the actuator of inflow water. The modeling of boiler drum, control approach and ANFIS controller design are detailed in section 3. Following that, validation of the proposed ANFIS controller is presented in section 4. In section 5, paper is concluded.

\section{Recent Related work: A Brief Review}

The water level controlling method plays a greater role in boiler drum for efficient performance. In literature, a very few works on steam generator of power plant are available in this regard. Some of them are reviewed here. M. Akkawi et al [21] have addressed the water level control problem of UTube Steam Generators (UTSG) of Nuclear Power Plants (NPP) through the design of an innovative set-point function. The set-point function was synthesized based on the inverse-control theory, which was able to improve the transient performance of the UTSG level subject to power adjustments. Based on the lead time between the power adjustment decision and the actual initiation of the adjustment, the proposed set-point function could apply appropriate control on the feed-water flow rate preemptively. This preemptive control action allowed the steam generator to prepare itself for the upcoming power change, i.e., steam flowrate change, to minimize the transient effects.
O. Safarzadeh et al [22] have presented a robust water level control system for the horizontal steam generator using the quantitative feedback theory (QFT) method. To design a robust QFT controller for the nonlinear uncertain steam generator, control oriented linear models were identified. Then, the nonlinear system was modeled as an uncertain linear time invariant (LTI) system. The robust designed controller was applied to the nonlinear plant model. This nonlinear model was based on a Locally Linear Neuro-Fuzzy (LLNF) model. This model was trained using the Locally Linear Model Tree (LOLIMOT) algorithm.

W. Tan [23] have proposed a water level control system for a nuclear steam generator. The control system consisted of a feedback controller and a feed forward controller. The feedback controller was of first order, the feed forward controller was of second order, and parameters of the two controllers were directly related to the parameters of plant model thus scheduling was easy to implement in practice. Robustness and performance of the feedback and the feed forward controllers were analyzed in details and tuning of the two parameters of the controllers was discussed.

H. Moradi et al [24] have implemented robust sliding mode and $\mathrm{H}_{\infty}$ control to achieve desired tracking of drum water level under transient conditions and in the presence of model uncertainties. Two transfer functions between drum water level (output variable); feed-water and steam mass rates (input variables) were considered. For the dynamic system with time varying characteristic and parametric uncertainties, a sliding mode controller was developed and an optimal $\mathrm{H}_{\infty}$ controller was designed based on $\mu$-synthesis with DK-iteration algorithm.

F. Fang et al [25] have proposed a steamgenerator water level control strategy based on an event-driven control methodology to lower the computing load of the control system and extend the service life of actuators. The theoretic stability analysis for a closed-loop system with an event detector was adequately expressed. The two-degreeof-freedom internal-model-control feedback controller and the dynamic feed forward controller, both of which were triggered by the same event detection logic, were designed to guarantee local performance. In addition, a gain-scheduling measure was adopted to combine local controllers to ensure the overall performance under all power levels.

L. Wei et al [26] have proposed an adaptive back stepping-based composite nonlinear feedback control scheme. The adaptive back stepping approach was used to design the water level 
controller and the feed water flow controller separately, formed a cascade control structure to overcome the load disturbance and feed water flow fluctuation. Furthermore, the composite nonlinear feedback control action was integrated into the feed water flow controller to accommodate the opening constraint of the feed water valve.

From the recent research works, the water level in the boiler of steam generator of nuclear or thermal power plant was controlled using Inverse Control theory, QFT, sliding mode \& $\mathrm{H}_{\infty}$ control, Event Driven control and Nonlinear Feedback control. The objective of these control algorithms was to follow the reference water level in the boiler drum to avoid the damage in terms of economic and human loss. The difficult task in these algorithms was to be robust for the shrink and swell phenomenon due to the transient changes in load requirement. This phenomenon was responsible for false measurement of water level which is not desirable as mentioned before. Therefore, the control algorithm must be able to withstand the false alarms due to the shrink and swell phenomenon and control the feed-water flow rate i.e., indirectly water level, as per the demanded pressure \& temperature of the boiler to meet the particular load. The mentioned techniques for water level control were complex both in the design procedures and implementation. This was not supported in the real time applications where control action needed in a short time. Hence, there was a scope for developing new control algorithms which could be simple and easy to design with faster performance. And, moreover, it must be robust to system parameters variations and sensor uncertainties. In literature, a very few works are presented on water level control of boiler considering the mentioned issues. The above mentioned problems have motivated me to do this research work.

\section{Design of ANFIS Controller for Water Level Regulation}

In this section, we have developed the ANFIS controller to regulate the water level in the boiler drum of a steam generator. It adjusts the valve point of feed water input to the boiler drum such that the water level tracks the set point given by GSO. Before designing the ANFIS controller, it is necessary to detail about boiler plant with its operation transients under shrink and swell phenomenon and contribution of proposed ANFIS controller. It is given as follows.

\subsection{Boiler Drum and Its Operation}

In power plants, steam generator acts an interface between primary side and secondary side where the primary side produces thermal energy while the secondary side uses that, to generate the steam by boiling water. This steam is then used to drive the turbine unit and followed by electric generator to produce electricity. As we know, the main component of steam generator is its boiler drum. The operation of the boiler is very critical because of the regulation of water level which should be in an acceptable range for the safe run of power plants. The operation of boiler is as follows.

In the boiler drum performance; there are various operating modes to be used by GSO: low, medium and high load modes. During the operation of these modes or transition between these modes, the steam flow requirement for the turbine unit changes to meet the demanded load. In such kinds of transition of steam flow, there are some dynamics of boiler to be considered. The main boiler dynamics to be controlled is its water level. It should be maintained within a narrow admissible range i.e., upper and lower limit values are to be determined before only. The violation of upper and lower limits will cause the severe effects on the boiler operation and leads to the instant power shut down by safety system installed in the power plant. This results in the unavailability of power plants and causes huge production and economic losses to consumers.

To prevent such tragedies, the control algorithm must be prepared for any kind of dynamic behavior of the boiler unit. In controlling the water level during load dynamics, shrink and swell phenomenon is the critical aspect to be given more attention. It contributes to the allowance of worst case scenario in the operation of boiler drum. This phenomenon gives the false water level measurement than the actual one as the shrink/swell effect in boiler level is actual but not apparent. It causes the unnecessary control requirement of feed water inflow. This unnecessary control action additionally increases or decreases the water level in boiler drum which leads to hazardous operation. However, it is worth mentioning that, during the boiler running process, even if the water supply flow and evaporation (steam) flow maintain a balance, the drum water level is possible to change because of the changing of the working fluid state rather than the amount of water within the drum.

The exact shrink and swell phenomenon is detailed as follows, if the steam flow increases suddenly due to the increased demand, the drum pressure drops quickly due to the outflow of steam from the boiler drum. This phenomenon is known as swell effect because of the swelling of steam 
bubbles underneath water surface. This would cause the water level to rise initially due to the expansion of water volume. On the contrary, the drum pressure gets increased accordingly and causes the steam bubbles underneath water surface but this time they are shrunken ones due to the excess steam presence in the boiler drum. This phenomenon is known as shrink effect in the boiler drum. This would cause the water level to drop due to contraction of water volume. If the demand is constant or small changes, the level will eventually return to the set point, otherwise, forcibly by control algorithm, it must be brought to the set point. In these circumstances, more complicated control strategy is necessary. Both the effects are influencing the drum pressure accordingly and changing of the Specific Heat Capacity of water and the number of air bubbles in steam drum, expansion or contraction of water volume, and then change of the water level.

Using this summary of the shrink and swell phenomenon in water boiler drum, here, we have developed ANFIS controller to provide the control response in opposite to cancel the shrink and swell effect. It is followed in the next subsection.

\subsection{Proposed System with ANFIS Controller}

In this subsection, it is discussed about the proposed approach for water level regulation by ANFIS controller. The block diagram of the proposed system is shown in figure 1.

In figure 1, the proposed ANFIS controller based boiler drum water level regulation is presented, in which, the three elements control approach is involved. The three elements are actual water level of the boiler drum, steam flow set point and actual feed water inflow. The significant contribution of the ANFIS controller is to process the given input elements and determine the appropriate control signal to water actuator such that it can withstand the false water alarm due to shrink and swell phenomenon. The water level regulation by ANFIS controller is shown in figure 2 .

In figure 2, the proposed approach for water level regulation by ANFIS controller is shown, in which, the inputs to the controller are error and change of error of actual and set point water level. The output of the ANFIS controller is control valve set point of the water actuator. The working procedure of the proposed system is given as; the actual water level of the boiler drum is fed back to the ANFIS controller in terms of its error and change of error. These inputs show the dynamic behavior of the water level in terms of its deviation from set point and rate change of that deviation.

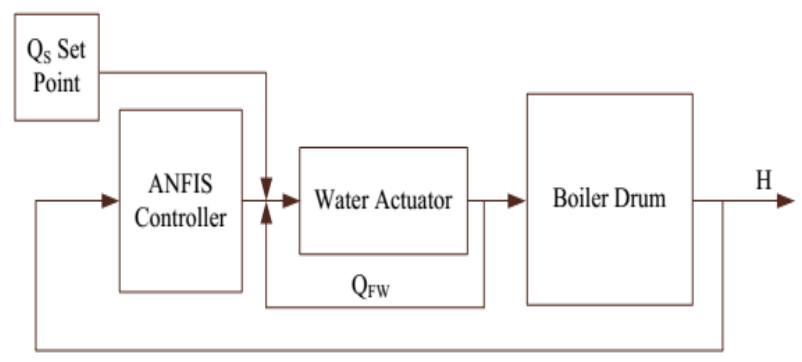

Figure.1 The proposed ANFIS controller in boiler drum

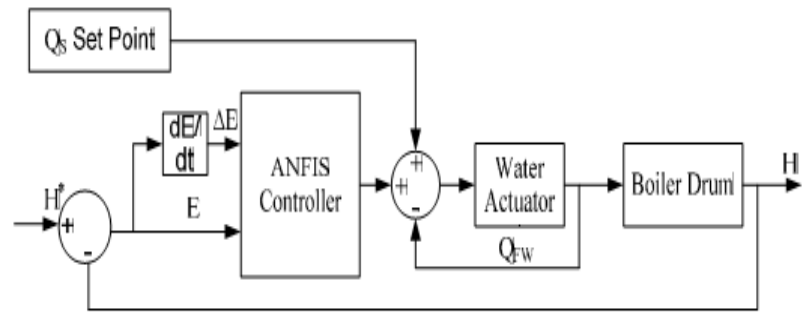

Figure.2 Proposed control approach by ANFIS controller

In steady state operation, if any changes occur in the water level error, it shows due to the working fluid changes in the boiler drum. So, ANFIS determines its output value according to the need of controlling actuator valve. But, during the dynamic operation, load value changes suddenly which is followed by the steam flow. In order to cop up the load variation, the changed steam set point value is given at the output of ANFIS controller. This gives the dynamic behavior of the proposed system during steam variations.

If the load demand is not varied, the change in steam value will be zero. Therefore, there is no need of extra support for the output of the ANFIS controller. For different operation modes, the proposed ANFIS controller gives the proper control value to the valve point of water actuator. Based on this actuator valve point, the feed water inflow is controlled in such a way that the water level achieves the set value. In this context, the design of the ANFIS controller is very important. The following subsection detailed the ANFIS controller typical structure for regulation purpose.

\subsection{Development of ANFIS Control}

In this subsection, we are going to design the proposed ANFIS controller. ANFIS is the AI technique which posses the abilities of Neural Network (NN) and Fuzzy Inference System (FIS). It is previously applied for multidisciplinary fields and specifically, use in control of machining processes such as Energy Conversion Systems, Communications, Power Systems, Smart Grid, Power and Industrial Electronics, etc. 


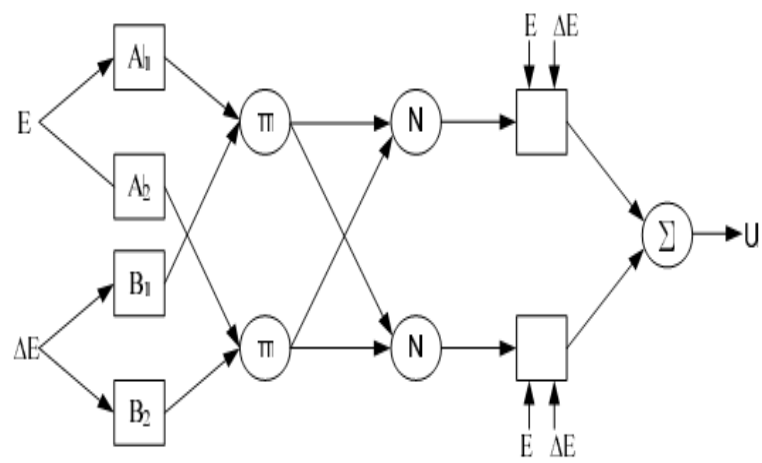

Figure.3 The Typical structure of ANFIS controller

It is well renowned because of robustness to the system uncertainties and provides faster response in any kind of situations for control processes. Therefore, we interested in studying the ANFIS controller performance for water level regulation in boiler drum. But, its design is the critical task which involves the determination of number of inputs and outputs, the training data and training algorithm.

For the proposed approach, from figure 2, the number of inputs and outputs are two and one respectively. They are error in the actual and set point water level and change of error value. Output of the ANFIS is controllable water actuator valve point. The typical structure of the ANFIS controller consists of five layers. Each layer performs a specific task for the processing of inputs to determine the concerned output. The typical structure of the proposed ANFIS controller is shown in figure 3.

In figure 3, the structure of proposed ANFIS controller is presented. It consists of five layers which are represented by square and circle shaped nodes. The square nodes are adaptive nodes and consist of tuning parameters. Here, $1^{\text {st }}$ and $4^{\text {th }}$ layers are the adaptive nodes and their tunable parameters are known as premise and consequent parameters respectively. The circle nodes are fixed nodes and no need of tuning for these nodes. Coming to the inputs of ANFIS five layers; the error and change of error are inputs to the ANFIS i.e., to its $1^{\text {st }}$ layer. The inputs to the $2^{\text {nd }}, 3^{\text {rd }}, 4^{\text {th }}$ and $5^{\text {th }}$ layers are the output of respective previous layers. And the output of $5^{\text {th }}$ layer is control valve set point i.e., ANFIS output. The performance of the accurate determination of output by ANFIS is greatly depends on the tuning of premise and consequent parameters. The determination of accurate parameters for ANFIS is performed by its training algorithm. Before going to that, the typical structure of the ANFIS controller is detailed clearly as follows [27-29].
First layer: Fuzzification of inputs

In this layer, the given inputs to the ANFIS controller are fuzzified. The fuzzified grade outputs of the ANIFS inputs are given as,

$$
\left.\begin{array}{l}
O_{1 i}=\mu_{A_{i}}(E) ; i=1,2 \\
O_{1 i}=\mu_{B_{i}-2}(\Delta E) ; i=3,4
\end{array}\right\}
$$

Where,

$\mathrm{O}_{\mathrm{li}}$ represents the output of $\mathrm{i}^{\text {th }}$ node in $1^{\text {st }}$ layer, $\mu_{A_{i}}$ and $\mu_{B_{i}-2}$ are the membership grades of fuzzy membership function for $E$ and $\Delta \mathrm{E}$ respectively. The membership function can be either bell shaped or Gaussian or triangular functions which contain the premise parameters and in need of tuning them.

Second layer: Product of incoming signals

In this layer, the outputs from the $1^{\text {st }}$ layer are taken as inputs and multiplied to provide the outputs. It is given as,

$$
O_{2 i}=\mu_{A_{i}}(E) \times \mu_{B_{i}}(\Delta E) ; i=1,2
$$

Where, $\mathrm{O}_{2 \mathrm{i}}$ represents the output of $\mathrm{i}^{\text {th }}$ node in $2^{\text {nd }}$ layer and is also called as firing strengths of the fuzzy rules. Here, nodes are represented as $\Pi$.

Third layer: Normalization of firing strengths

In this layer, the outputs of $2^{\text {nd }}$ layer are taken as inputs and normalized as given below,

$$
O_{3 i}=\frac{O_{2 i}}{\sum O_{2 i}} ; i=1,2
$$

Where, $\mathrm{O}_{3 \mathrm{i}}$ represents the output of $\mathrm{i}^{\text {th }}$ node in $3^{\text {rd }}$ layer and is also known as the normalized firing strength. Here, nodes are represented as N.

Fourth layer: Determination of Sugeno Inference model output

In this layer, the outputs of $3^{\text {rd }}$ layer are taken as inputs along with the ANFIS inputs too. The output of $4^{\text {th }}$ layer is the product of Sugeno model output value and $3^{\text {rd }}$ layer outputs. It is given as,

$O_{4 i}=O_{3 i} \times f_{i}=O_{3 i} \times\left(p_{i} \cdot E+q_{i} \cdot \Delta E+r_{i}\right) ; i=1,2$

Where, $\mathrm{O}_{4 \mathrm{i}}$ represents the output of fourth layer, $f_{i}$ is the sugeno model output for the given inputs, and its parameters, namely, consequent parameters are $\mathrm{p}_{\mathrm{i}}, \mathrm{q}_{\mathrm{i}}, \mathrm{r}_{\mathrm{i}}$.

Fifth layer: Summation of inputs

In this layer, the outputs of the $4^{\text {th }}$ layer are given as inputs and are summed together to give a single output. It is given as,

$$
O_{5 i}=\sum_{i} O_{4 i} ; i=1,2
$$


Where, $\mathrm{O}_{5 \mathrm{i}}$ represents the output of $5^{\text {th }}$ layer of ANFIS,

This is summary of typical structure of proposed ANFIS with first order Sugeno inference model which is given as,

$$
\left.\begin{array}{l}
\text { Rule } 1 \text { :If } E \text { is } A_{1} \text { and } \Delta E \text { is } B_{1}, \\
\text { then } f_{1}=p_{1} E+q_{1} \Delta E+r_{1} \\
\text { Rule } 2: \text { If } E \text { is } A_{2} \text { and } \Delta E \text { is } B_{2}, \\
\text { then } f_{2}=p_{2} E+q_{2} \Delta E+r_{2}
\end{array}\right\}
$$

Where, Rule1 and Rule2 are the examples of working process of first order Sugeno model. Based on these rules, $4^{\text {th }}$ layer will determine the inputs to the $5^{\text {th }}$ layer. For better performance of the ANFIS, these consequent parameters $\left(\mathrm{p}_{\mathrm{i}}, \mathrm{q}_{\mathrm{i}}, \mathrm{r}_{\mathrm{i}}\right)$ are tuned properly by the training algorithm. The number of fuzzy rules in ANFIS controller depends on the number of linguistic grades in the membership functions of inputs and outputs used by the user. For training the ANFIS controller, there are several algorithms such as back propagation algorithm, least square estimator, steepest descent, etc. Utilizing one of the learning algorithms, the error between the target output and actual output of ANFIS controller will be minimized to a negligible value and tested with actual data for good response. Once, the ANFIS controller is developed, it is ready to provide the control valve set point to the water actuator for controlling the water level in boiler drum. The performance of the proposed ANFIS controller for boiler drum is validated in the next section with details of its design.

\section{Results and Discussions}

In this section, we have discussed the performance of the proposed ANFIS controller for water regulation. The performance of the proposed controller is tested in MATLAB working platform. For this attention, the boiler drum system is developed in terms of transfer functions of water inflow effect on height of water level and steam flow fluctuations i.e., varying load demands. Based on this transfer functions, the proposed ANFIS controller is employed in the boiler drum system and validated in terms of tracking the set point of water level. Before, validating the performance of the ANFIS controller, the SIMULINK model of the boiler system and ANFIS controller development is discussed. The SIMULINK model of the boiler drum with the proposed ANFIS controller is given in figure 4 .

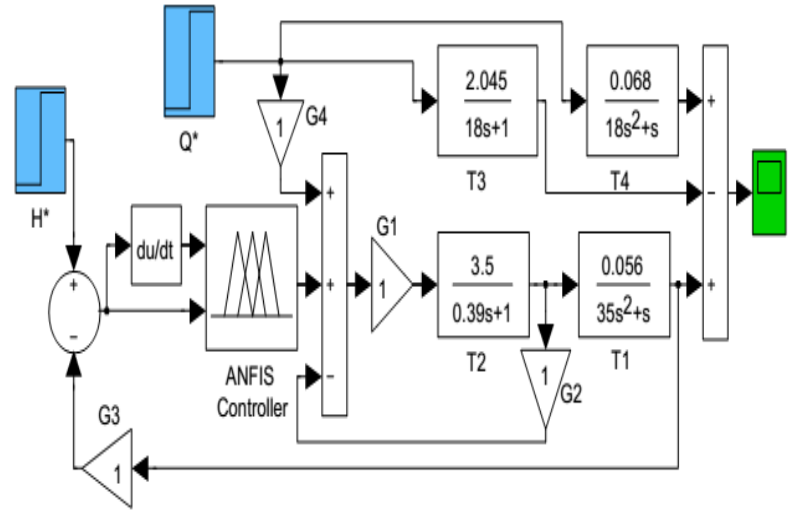

Figure.4 The SIMULINK model of the proposed system

Table 1. The relation between the transfer functions and boiler model

\begin{tabular}{|c|c|c|}
\hline $\begin{array}{c}\text { Transfer } \\
\text { Function No. }\end{array}$ & Denotation & Purpose \\
\hline 1 & T1 & $\begin{array}{c}\text { Effect water inflow } \\
\text { on water level }\end{array}$ \\
\hline 2 & T2 & $\begin{array}{c}\text { Effect of water } \\
\text { actuator valve on } \\
\text { water inflow }\end{array}$ \\
\hline 3 & T3 & $\begin{array}{c}\text { Effect of steam flow } \\
\text { on water level }\end{array}$ \\
\hline 4 & T4 & $\begin{array}{c}\text { Effect of steam flow } \\
\text { on water level }\end{array}$ \\
\hline
\end{tabular}

In figure 4, the SIMULINK model of proposed system is presented, in which, boiler model operation is shown in its transfer function models. The detail of the transfer functions are presented in table 1.

In table 1 , the relation between the transfer functions and boiler model I detailed. As mentioned, in table 1 , the $\mathrm{T} 1$ transfer function provides the water level when the inflow of the water is determined. It is determined by $\mathrm{T} 2$ transfer function from its input control signal provided by the ANFIS controller. Based on these transfer functions, the performance of the proposed ANFIS controller is analyzed. The performance of the proposed controller is analyzed in terms of water level tracking capability. It is also compared with PID controller and Fuzzy logic controller for showing the superior nature. The comparison is analyzed in terms of error deviation performance by each controller. 


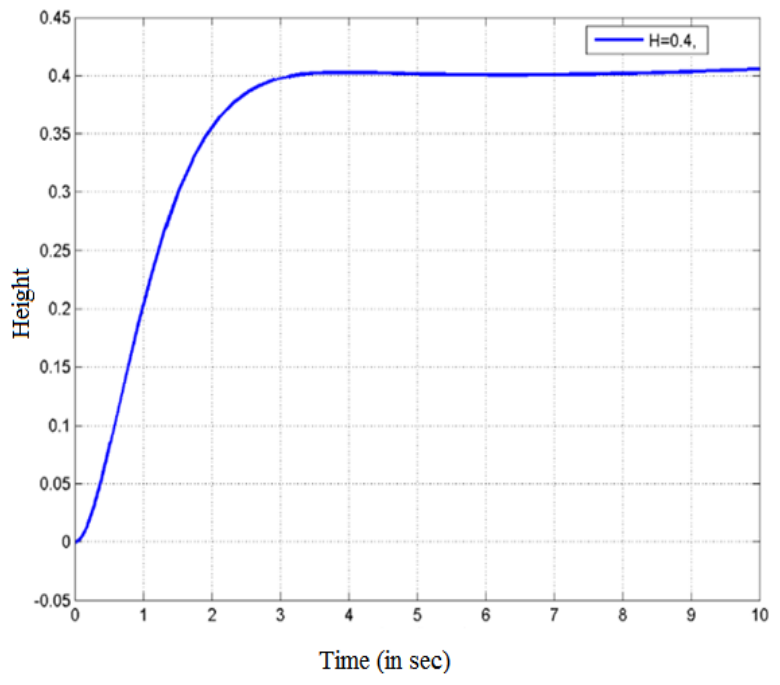

Figure.5 The Performance of the proposed ANFIS controller for set step size 0.4 .

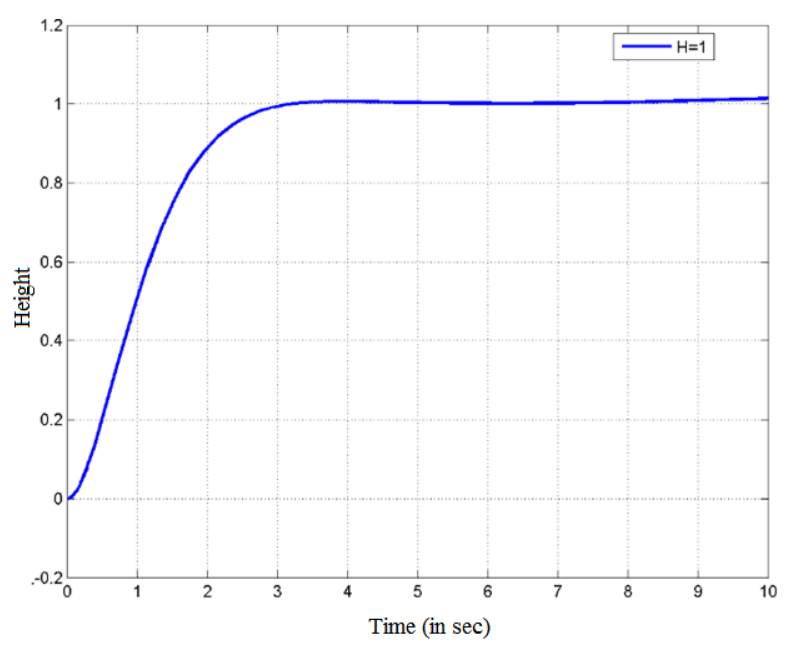

Figure.6 The Performance of the proposed ANFIS controller for set step size 1 .

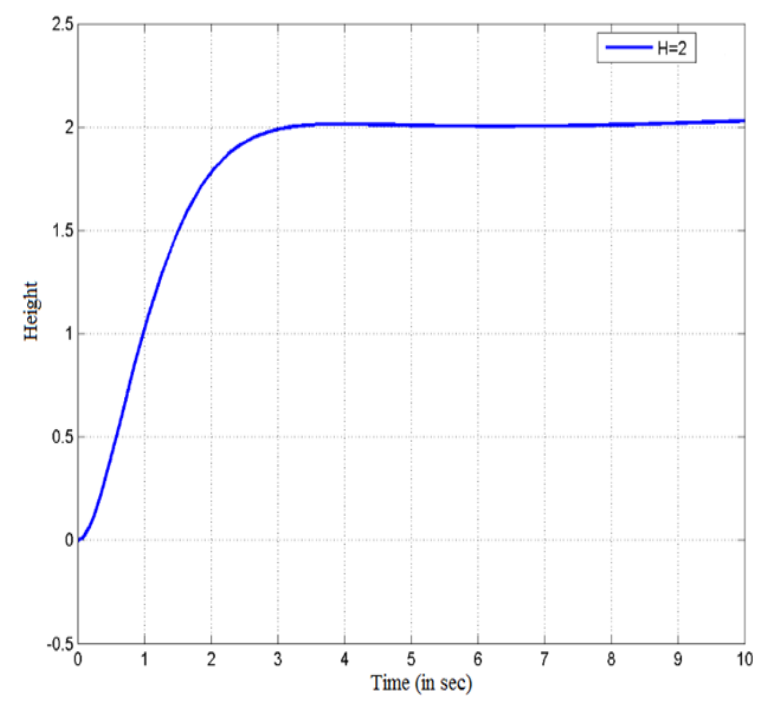

Figure.7 The Performance of the proposed ANFIS controller for set step size 2 .

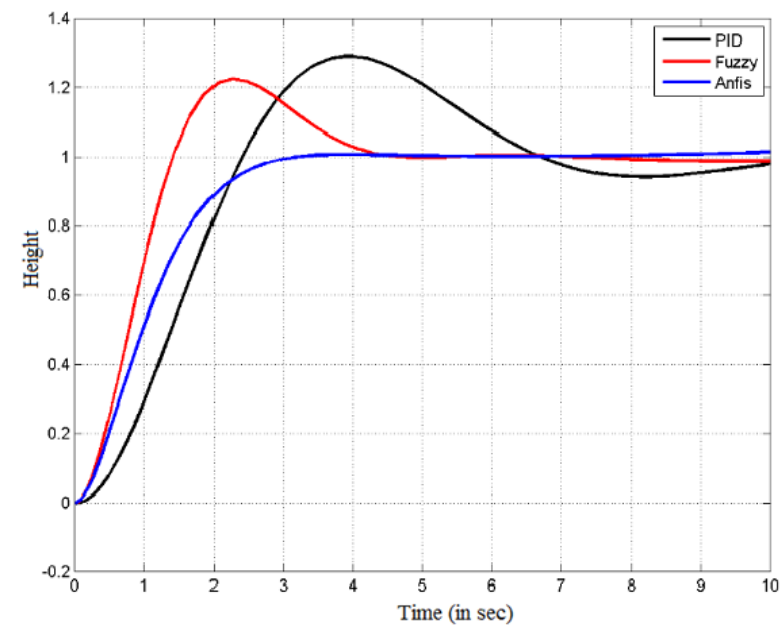

Figure. 8 The performance of the three controllers for unit step of water level

In the proposed system's SIMULINK model, the steam flow and water level set functions are given as step functions. Based on these step functions the performance of these three controllers is performed. Now, the performance of the proposed controller is analyzed for different set points of water level in the boiler drum. For this purpose, the water level regulation by ANFIS controller is checked for set point of step inputs for sizes of 0.4 , unit and 2 . The performance graphs are shown in figure 5, 6 and 7 respectively.

From figures 5, 6 and 7, the performance of the proposed ANFIS is analyzed in terms of tracking the water level set point. From those figures, it says that, for the give step size of water level, the ANFIS controller tracked water level accurately and within the short period of time. This shows the accurate performance of the proposed controller in tracking the water level thus good regulation. Now, the performances of the fuzzy and PID controller are compared with ANFIS controller. First, a unit step input is applied to the proposed boiler model and checked the performance of each controller without any disturbances from steam flow i.e., no load variations. The unit step response of each controller is shown in figure 8 .

In figure 8 , the performances of the proposed ANFIS, Fuzzy controller and PID controller are presented. From the figure 8, it shows that, the performance of the PID controller is having large overshoot and more time than the both Fuzzy and ANFIS controller for first peak. It is also not reached the set unit point in the given period of time. Similarly, in fuzzy controller performance, the overshoot is higher than the proposed one, and its settlement time is also more than the proposed ANFIS controller. 
Table 2. The water level deviation from set point by

\begin{tabular}{|c|c|c|c|c|c|c|c|}
\hline \multicolumn{8}{|c|}{ ANFIS, PI and FIS } \\
\hline \multirow[b]{2}{*}{$\begin{array}{l}\mathrm{Ti} \\
\mathrm{me} \\
\text { ( se } \\
\mathrm{c})\end{array}$} & \multirow[b]{2}{*}{$\begin{array}{l}\text { Water } \\
\text { level } \\
\text { set } \\
\text { point }\end{array}$} & \multicolumn{2}{|c|}{ ANFIS } & \multicolumn{2}{|c|}{\begin{tabular}{|l|} 
FIS \\
\end{tabular}} & \multicolumn{2}{|c|}{ PID } \\
\hline & & \begin{tabular}{|c|} 
Error \\
devia \\
tion \\
$(\mathrm{mm})$ \\
\end{tabular} & $\begin{array}{c}\text { Settle } \\
\text { ment } \\
\text { time } \\
(\mathrm{sec})\end{array}$ & $\begin{array}{c}\text { Error } \\
\text { deviati } \\
\text { on } \\
(\mathrm{mm})\end{array}$ & $\begin{array}{c}\text { Settle } \\
\text { ment } \\
\text { time } \\
(\mathrm{sec})\end{array}$ & $\begin{array}{c}\text { Error } \\
\text { deviati } \\
\text { on } \\
(\mathrm{mm})\end{array}$ & $\begin{array}{c}\text { Settle } \\
\text { ment } \\
\text { time } \\
(\mathrm{sec})\end{array}$ \\
\hline 1 & 1.0 & 0.50 & \multirow{10}{*}{3} & 0.30 & \multirow{10}{*}{4.5} & 0.70 & \multirow{10}{*}{10} \\
\hline 2 & 1.0 & 0.10 & & -0.20 & & 0.20 & \\
\hline 3 & 1.0 & 0.00 & & -0.15 & & -0.20 & \\
\hline 4 & 1.0 & 0.00 & & -0.05 & & -0.30 & \\
\hline 5 & 1.0 & 0.00 & & 0.00 & & -0.20 & \\
\hline 6 & 1.0 & 0.00 & & 0.00 & & -0.10 & \\
\hline 7 & 1.0 & 0.00 & & 0.00 & & 0.02 & \\
\hline 8 & 1.0 & 0.00 & & 0.00 & & 0.07 & \\
\hline 9 & 1.0 & 0.00 & & 0.00 & & 0.04 & \\
\hline 10 & 1.0 & 0.00 & & 0.00 & & 0.00 & \\
\hline
\end{tabular}

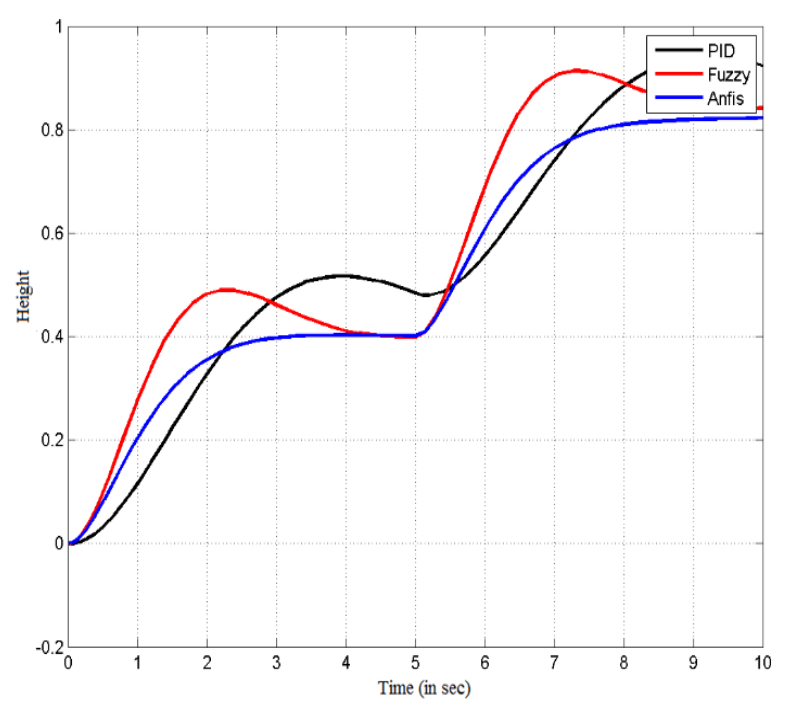

Figure.9 The Dynamic performance of the three controllers

The performance comparison is tabulated in table 2 for better understanding of the ANFIS controller superiority. In table 2, the performance of ANFIS and other controllers are presented in terms of error deviation from the water level set point.

The table 2 shows that the, proposed ANFIS controller has faster settling time than the fuzzy and PID controllers. From this comparison, it says that the proposed ANFIS controller is better controller than fuzzy controller and PID controller is regulating the water level in boiler drum.

Now, the dynamic performance of the proposed controller is analyzed for step change in water level set point. For this purpose, the set of water level is changed from 0.4 to 0.8 unit step and analyzed the performance of the three controllers. The responses of the controllers are shown in figure 9.

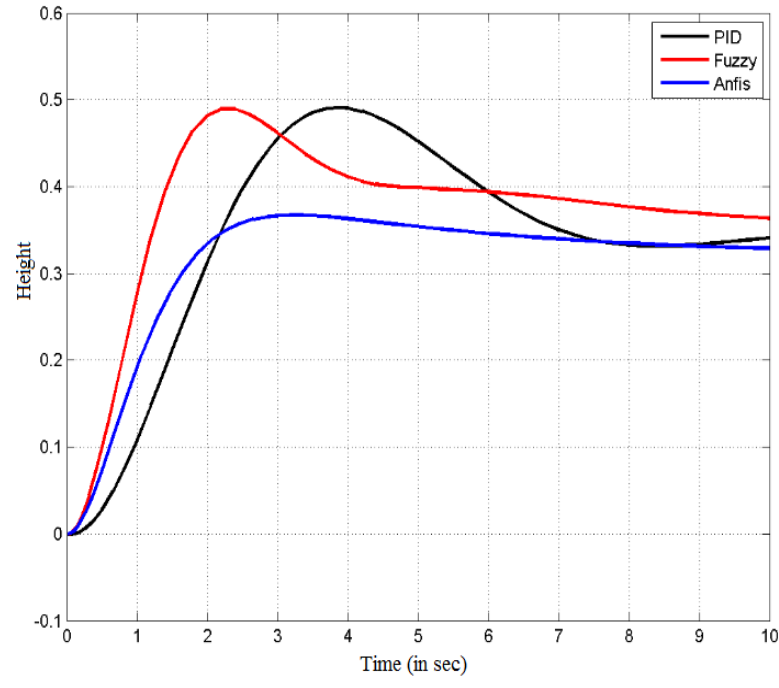

Figure.10 The water level regulation performance of three controllers for steam flow changes

In figure 9, the performance of the ANFIS, Fuzzy and PID controllers for change in set point of water level is presented. From figure 9, it says that, the proposed ANFIS controller has faster response and lesser overshoot the other two controllers. The tracking performance for change in set point of water level is also achieved accurately by the proposed controller than other ones. This shows the superior quality of the proposed controller in accurate and faster tracking of water level of the boiler drum

Now, the performance of the proposed ANFIS controller is analyzed in terms of cancelling the shrink and swell effect. For this purpose, the set point of steam flow step size is changed from 0.06 to 0.1 and water level is set at step size of 0.4 . With these settings, the performance of ANFIS and other controllers for water level regulation is checked. The performance comparison of water level regulation is shown in figure 10 .

In figure 10, the dynamical performance of the proposed ANFIS and other controllers is presented for dynamical change in steam flow. From figure 10, it says that, the proposed controller has lower deviation from the set point of water level than other controllers when steam flow is disturbed. This shows that the proposed controller can effectively cancel out the shrink and swell effect during steam changes.

\section{Conclusion}

In the paper, the regulation of water level in a boiler drum was achieved by ANFIS controller. The error and change of error between the set value and actual of water level were given as inputs and the 
actuator control valve was taken as output. From the determination of valve point by ANFIS controller, boiler drum level was regulated. The performance of ANFIS controller was performed in MATLAB/SIMULINK platform and analyzed in terms of tracking the water level of boiler drum. The performance of the proposed ANFIS controller was compared with Fuzzy and PID controllers to show its superiority. From the simulation results, it was showed that the proposed ANFIS controller was the better solution the fuzzy and PID controllers for water level regulation in the boiler drum. In future water level control in the boiler drum has been possible by the new meta-heuristic algorithms and will enhance the control performances.

\section{References}

[1] F. Alobaid, S. Pfeiffer, B. Epple, C. Y. Seon and H. G. Kim, "Fast start-up analyses for Benson heat recovery steam generator", Energy, Vol. 46, pp. 295309, 2012

[2] S. Espatolero, C. Cortés and L. M. Romeo, "Optimization of boiler cold-end and integration with the steam cycle in supercritical units", Applied Energy, Vol. 87, pp. 1651-1660, 2010

[3] A. Behbahani-nia, M. Bagheri and R. Bahrampoury, "Optimization offire tube heat recovery steam generators for cogeneration plants through genetic algorithm", Applied Thermal Engineering, Vol. 30, pp. 2378-2385, 2010

[4] F. Alobaid, J. Ströhle, B. Epple and H. G. Kim, "Dynamic simulation of a supercritical once-through heat recovery steam generator during load changes and start-up procedures", Applied Energy, Vol. 86, pp. 1274-1282, 2009

[5] E. Norouzi and M. Amidpour, "Optimal thermodynamic and economic volume of a heat recovery steam generator by constructal design", International Communications in Heat and Mass Transfer, Vol. 39, pp. 1286-1292, 2012

[6] M. D. Durán, M. Valdés, A. Rovira and E. Rincón, “A methodology for the geometric design of heat recovery steam generators applying genetic algorithms", Applied Thermal Engineering, Vol. 52, pp. 77-83, 2013

[7] A. Sogni and P. Chiesa, "Calculation code for helically coiled heat recovery boilers", Energy Procedia, Vol. 45, pp. 492-501, 2014

[8] P A. Kew and K. Cornwell, "Development of a highly compact steam generator", Applied Thermal Engineering, Vol. 25, pp. 2604-2614, 2005

[9] M. Kljajic, D. Gvozdenac and S. Vukmirovic, "Use of Neural Networks for modeling and predicting boiler's operating performance", Energy, Vol. 45, pp. 304-311, 2012

[10] A. Rahmani, T. Bouchami, S. Bélaïd, A. B. Salah and M. H. Boulheouchat, "Assessment of boiler tubes overheating mechanisms during a postulated loss of feedwater accident", Applied Thermal Engineering, Vol. 29, pp. 501-508, 2009

[11] M. Mogharia, S. Hosseini, H. Shokouhmand, H. Sharifi and S. Izadpanah, "A numerical study on thermal behavior of a D-type water-cooled steam boiler", Applied Thermal Engineering, Vol. 37, pp. 360-372, 2012

[12] L. Nogueira F. Guimara es, Nilton da Silva Oliveira $\mathrm{Jr}$ and Eduardo Madeira Borges, "Derivation of a nine variable model of a U-tube steam generator coupled with a three-element controller", Applied Mathematical Modelling, Vol. 32, pp. 1027-1043, 2008

[13] R. Kumar and N. Idvorian, "Considerations for structural analysis and evaluations of nuclear steam generator internals", International Journal of Pressure Vessels and Piping, Vol. 78, pp. 359-364, 2001

[14] H. Moradi and F. B. Nejad, "Improving boiler unit performance using an optimum robust minimumorder observer", Energy Conversion and Management, Vol. 52, pp. 1728-1740, 2011

[15] A. Bahadori and H. B. Vuthaluru, "A method for estimation of recoverable heat from blowdown systems during steam generation", Energy, Vol. 35, pp. 3501-3507, 2010

[16] H. E. Emara-Shabaik, M. A. Habib and I. A. Zaharna, "Prediction of risers' tubes temperature in water tube boilers", Applied Mathematical Modeling, Vol. 33, pp. 1323-1336, 2009

[17] S. Aliakbari, M. Ayati, J. H. S. Osman and Y. M. Sam, "Second-order sliding mode fault-tolerant control of heat recovery steam generator boiler in combined cycle power plants", Applied Thermal Engineering, Vol. 50, pp. 1326-1338, 2013

[18] H. Moradi, A. Alasty and G. Vossoughi, "Nonlinear dynamics and control of bifurcation to regulate the performance of a boiler-turbine unit", Energy Conversion and Management, Vol. 68, pp. 105-113, 2013

[19] K. J. AsstroKm and R. D. Bell, "Drum-boiler dynamics", Automatica, Vol. 36, pp. 363-378, 2000

[20] K. Hu and J. Yuan, "Multi-model predictive control method for nuclear steam generator water level", Energy Conversion and Management, Vol. 49, pp. 1167-1174, 2008

[21] M. Akkawi and J. Jiang, “An Inverse Control-Based Set-Point Function for Steam Generator Level Control in Nuclear Power Plants", IEEE Transactions on Nuclear Science, Vol. 58, No. 6, pp. 3291-3304, 2011

[22] O. Safarzadeh, A. K. Sedigh and A. S. Shirani, "Identification and robust water level control of horizontal steam generators using quantitative feedback theory", Energy Conversion and Management, Vol. 52, No. 10, pp. 3103-3111, 2011

[23] W. Tan, "Water level control for a nuclear steam generator", Nuclear Engineering and Design, Vol. 241, No. 5, pp. 1873-1880, 2011 
[24] H. Moradi, M. S. Avval and F. B. Nejad, "Sliding mode control of drum water level in an industrial boiler unit with time varying parameters: A comparison with $\mathrm{H}_{\infty}$-robust control approach", Journal of Process Control, Vol. 22, No. 10, pp. 1844-1855, 2012

[25] F. Fang and Y. Xiong, "Event-Driven-Based Water Level Control for Nuclear Steam Generators", IEEE Transactions on Industrial Electronics, Vol. 61, No. 10, pp. 5480-5489, 2014

[26] L. Wei, F. Fang and Y. Shi, "Adaptive Backstepping-Based Composite Nonlinear Feedback Water Level Control for the Nuclear U-Tube Steam Generator", IEEE Transactions on Control Systems Technology, Vol. 22, No. 1, pp. 369-377, 2014

[27] Z. Yun, Z. Quan, S. Caixin, L. Shaolan, L. Yuming and S. Yang, "RBF Neural Network and ANFISBased Short-Term Load Forecasting Approach in Real-Time Price Environment", IEEE Transactions on Power Systems, Vol. 23, No. 3, pp. 853-858, 2008

[28] I. M. Ginarsa, A. Soeprijanto and M. H. Purnomo, "Controlling chaos and voltage collapse using an ANFIS-based composite controller-static var compensator in power systems", Electrical Power and Energy Systems, Vol. 46, pp. 79-88, 2013

[29] A. Subasi, "Application of adaptive neuro-fuzzy inference system for epileptic seizure detection using wavelet feature extraction", Computers in Biology and Medicine, Vol. 37, pp. 227-244, 2007 